\title{
Um Olhar Semiótico sobre o teatro de Animação
}

\section{Cristine Medeiros Esmeraldino'}

\section{Resumo:}

Este Artigo tem como objetivo chamar a atenção e refletir sobre os aspectos significativos que se acham entrelaçados no Teatro e, paralelamente, chamar a atenção para 0 Teatro de Animação. Trata-se de uma forma de teatro, mas define-se em características próprias. São apresentados os "signos", "códigos" ou elementos constitutivos do teatro convencional para, então, mostrar que aspectos se modificam no Teatro de Animação, especialmente no que diz respeito à recepção do público, ou seja, no fenômeno de significar. Conclui mostrando a importância de se estar atento ao potencial significativo do espetáculo de Teatro de Animação, de modo a melhor explorar e realizar este potencial.

Refletir sobre o teatro de animação sob a perspectiva teórica da semiótica significa preocupar-se com a questão da recepção ou, simplesmente, com a significação do espetáculo de animação.

Segundo HOUDART (2000, p. 41-46),

as artes do espetáculo, o teatro, a marionete, a dança, a música, pelo menos nos artistas mais autênticos, convergem para um movimento difuso e informal cuja constante é a utilização das marionetes, das figuras - da palavra latina figura, que significa representação. Pleonasmo? Certamente não, mas precisão bem útil e que significa que o teatro reencontra o sentido do signo, que nunca deveria ter perdido, que no teatro tudo é signo - a palavra e o corpo, o espaço e o objeto, o movimento e a luz -, e no teatro que ignora essa linguagem simbólica é apenas uma deriva duvidosa.

A arte teatral é um objeto semiótico por natureza. O conceito do que entendemos atualmente por teatro é originário do verbo grego "theastai" (ver, contemplar, olhar). A noção de representação está vinculada ao ritual mágico e religioso primitivo e é tão antigo quanto o homem. Muitos estudiosos acreditam que o teatro nasceu no instante em que o homem primitivo colocou e tirou a máscara

\footnotetext{
${ }^{1}$ Graduanda do Curso de Educação Artística-Licenciatura em Artes Plásticas
} 
diante do espectador, com plena consciência do exercício de "simulação", de "representação", ou seja, do signo.

Para que se reflita acerca de algumas distinções entre o teatro propriamente dito e o teatro de animação, é necessário relembrar algumas noções acerca dos signos teatrais, para então destacar algumas características do teatro de animação.

Os "signos", segundo alguns autores, "códigos", segundo outros, ou principais elementos constitutivos que compõem o teatro dito convencional e o teatro de animação são os seguintes:

\section{Cenário}

Enquanto sistema semiótico, o cenário determina o tempo e o espaço da ação teatral. No entanto, para se entender a linguagem cenográfica, é preciso recorrer a outros sistemas artísticos, como a pintura, a escultura, a arquitetura, a decoração e o design da iluminação. São esses sistemas que se encarregam de representar um espaço geográfico, um espaço social ou um espaço interior. Os recursos cenográficos também podem estar na performance do ator, no ruído, no vestuário ou na iluminação. No teatro de animação o cenário tem a mesma função que no teatro convencional, isto é, o cenário ajuda a representar um espaço geográfico, um espaço social ou um espaço interior.

Gesto

Um dos organizadores fundamentais da gramática teatral é o gesto. Através do gesto e da voz o ator cria a personagem (do latim persona). Tornou-se um instrumento indispensável na arte teatral, através de um sistema de signos que exprime pensamentos através do movimento ou atitude da mão, do braço, da perna, da cabeça ou do corpo inteiro. Os signos gestuais podem acompanhar ou substituir 
a palavra, suprimir um elemento do cenário, um acessório, um sentimento ou emoção.

No teatro de animação o gesto também é um elemento importante, só que ao invés de ser o ator a fazer o gesto, é o boneco que o faz. Ao animar o boneco, o ator/animador da vida a um ser inanimado, e esse boneco gesticula como o personagem que é.

Pode existir ainda uma combinação do corpo do ator com pernas mecânicas e outros adereços e apêndices, formando uma espécie de monstro metade biológico, metade ortopédico ou, metade matéria viva, e metade inerte. É a idéia, de supermarionete: ao gesticular seria algo realmente divino, e nenhum ser humano seria capaz de gesticular da mesma forma.

lluminação

A introdução da iluminação na arte teatral deu-se apenas no século XVII, o que se comparada a outros sistemas signicos teatrais, é relativamente recente. Delimitar o espaço cênico é a principal função da iluminação. Quando um facho de luz incide sobre um determinado ponto do palco, significa que é ali que a ação se desenrolará naquele momento. Além de delimitar o lugar da cena, a iluminação se encarrega de estabelecer relações entre 0 ator e os objetos; 0 ator e os personagens em geral. A iluminação "modela" através da luz o rosto, o corpo do ator ou um fragmento do cenário. As cores difundidas pela iluminação é um outro recurso que também permite uma leitura semiótica.

Movimento cênico 
As várias maneiras de o ator se deslocar no espaço cênico, suas entradas e saídas ou sua posição com relação aos outros atores, aos acessórios, aos elementos do cenário ou até mesmo aos espectadores, podem representar os mais variados signos. A movimentação tanto cria a unidade do texto teatral como organiza e relaciona as seqüências no espaço cênico.

No teatro de animação o movimento cênico tem o mesmo sentido que no teatro “convencional”, só que no lugar do ator é o boneco que se movimenta. Claro é que o espaço cênico é muito mais reduzido, o que faz com que a carga semântica aumente de intensidade. Por este motivo, os movimentos não podem ser ambíguos; ao contrário, devem ser claros, precisos e sintéticos.

Música

A música é o elemento que dialoga com o texto teatral, com os movimentos do ator ou do ser animado (bonecos, sombras, objetos, máscaras), explicita seu estado interior, contracena com a luz, e com o espaço em todos os seus aspectos. A música sempre esteve presente no teatro, desde há muito tempo. O diretor de uma peça pode utilizar a música, acrescentada a outros signos, para enfatizar, ampliar, desenvolver, desmentir ou substituir outros signos. Também pode utilizar a música para significar a entrada e a saída de um certo personagem de cena.

\section{Voz}

A performance, que pode ser considerada a linguagem primária do teatro, é criada pela voz em conjunto com o gesto. Elemento básico do texto teatral, escrito 
ou não a voz, é utilizada pelo ator para dar vida ao personagem. Ela atua como uma "fronteira de liberdade" que o ator explora a seu modo, através da entoação, do ritmo, da rapidez e da intensidade com que ele pronuncia as palavras antes apenas escritas, criando desta forma, os mais variados signos.

No teatro de animação, muitas vezes as vozes são gravadas antes da encenação, e é só reproduzida no momento da apresentação. O ator/dublador que faz a voz do personagem muitas vezes não é o mesmo ator/animador, mesmo quando a voz é feita na hora da apresentação.

\section{Enredo}

De acordo com Sandra RAMALHO E OLIVEIRA(1998), em sua tese de doutorado,

enredo é o conjunto de circunstâncias e acontecimentos articulados em um espetáculo cênico. Como em geral, confundem-se com as cenas, enredo pode ser considerado o conjunto das cenas do espetáculo. Difere de história, uma vez que esta seria a seqüência temporal dos acontecimentos. A história corresponde à leitura horizontal ou linear; o enredo, à leitura vertical ou paradigmática, onde o importante é o modo como os fatos da história são considerados.

A autora segue citando Patrice Pavis. Assim, ela acrescenta, à noção de enredo, aspectos que possibilitam a análise do espetáculo:

no que toca ao enredo, Pavis indica que se deve analisar o que ele contou; que tipo de escolhas foram feitas, em termos de dramaturgia; quais as ambigüidades encontradas na interpretação e quais os pontos que ficaram bem esclarecidos; como a marcação foi estruturada; como a história foi construída pelos atores e pelos demais elementos significantes em cena; qual o gênero do texto dramático. 
A recepção no Teatro de Bonecos

O teatro de animação também tem seus signos/códigos/elementos próprios e difere do convencional principalmente por não ser o ator que interpreta o personagem, e sim esse ator anima um ser inanimado.

Por outro lado, o boneco é um personagem, diferente do ator que faz vários personagens. Este simples fato faz com que a carga semântica inerente às características identitárias, bem como suas funções no enredo sejam sublinhadas.

Sendo feito de diferentes materiais, o objeto inanimado participa da condição de uma espécie de morte e, ao ser animado, participa da vida; dessa forma, ele pode transmitir, através deste movimento, a expressão máxima da vida humana.

Por ser duplo, ele é e não é, adquirindo uma superioridade, ao ator, pois este tem um cuidado especial em reproduzir a realidade, desta forma a imagem recebida pelo observador perde credibilidade.

O teatro de animação também difere na importância que tem cada signo/código, pois ao contrário do teatro convencional no teatro de animação a imagem é mais importante que o texto. No entanto, é necessário cuidado quanto a isso, pois mesmo a imagem sendo o signo/código que rege o teatro de animação, é necessário que se tenha uma dramaturgia adequada para esta linguagem específica como base do espetáculo. Pois existem muitas peças que acabam ficando pobres e sendo um desfile de elementos visuais, cada objeto colocado em cena deve ter uma boa razão para estar ali. 
O teatro de animação é a arte onde mais existe a interligação entre as diversas linguagens artísticas, para ler uma peça de teatro de animação é necessário ser alfabetizado em artes plásticas, música e artes cênicas. Conseguindo ler seus elementos constitutivos-nas artes plásticas: cor, linha, ponto, volume, dimensão, textura, plano, forma; nas artes cênicas: gestual, verbal, iluminação, Som (musica, sonoplastia), cenário, figurino, maquiagem; e na música: Timbre, Intensidade, Altura, Duração. Esses efeitos constitutivos que sendo relacionados vão dar os efeitos de sentido, e nos fazer entender a peça.

Enfim, Como falou Álvaro Apocalipse em entrevista dada a Folha de São Paulo em 20 de junho de 1998:

\footnotetext{
No teatro que nós fazemos, a ênfase é muito grande no visual, porque são outras formas de transmitir a emoção, de criticar, de sensibilizar as pessoas.

E no teatro, em geral, a primeira grande preocupação é o texto. Nós partimos da imagem, que não se sabe de onde vem, e evoluímos combinando tudo - o texto, a música, o movimento... Alguém, não me lembro mais quem foi, disse algo que eu acho perfeito: no teatro se representa, no teatro de bonecos se é. Você é João e faz no palco o rei Salomão. Nós não, nós colocamos no palco o rei Salomão, não existe o João.
}

Últimas Considerações - a título de conclusão

Portanto, o que se quis destacar aqui é a importância de se estar atento ao potencial significativo do espetáculo de Teatro de Animação, de modo a melhor explorar e realizar este potencial.

Tudo é mais conciso, mais específico e, portanto, cada um dos signos, códigos ou elementos constitutivos do teatro é mais carregado de significações; é como se os significados estivessem concentrados em espaço e tempo menores em uma escala, em relação ao teatro convencional. 
É necessário desta forma que cada detalhe, cada elemento colocado em cena, seja extremamente estudado e bem trabalhado. Cuidando além da linguagem visual, que já foi evidenciado como a mais importante, das demais linguagens, principalmente aperfeiçoando a dramaturgia para que se tenha qualidade teatral.

Como colocou Dominique Houdart em seu ensaio Manifesto por um teatro de marionete e de figura, 41-46,2000:

Dizer que se trata de uma linguagem de signos não é suficiente, visto que o teatro todo é-ou deveria ser-uma linguagem de signos. Mas para precisar melhor, poder-seia dizer que se trata de uma linguagem de signos conscientes não a arte pela arte, mas a arte pelo significado, não a apresentação, mas a representação, não a exposição, mas a transposição.

A arte do Teatro de Animação é uma arte milenar, e muito valorizada no mundo oriental. No entanto no mundo ocidental está relegada a segundo plano, discriminada, colocada como apenas teatro infantil. É necessário que se pesquise mais sobre essa arte, que é considerada por alguns estudiosos como uma arte mágica. Através da teoria dos signos pode-se descobrir mais sobre esta linguagem, e ao estuda-la descobrir um mundo novo, cheio de signos e significados transcendentais.

Bibliografia:

AMARAL, Ana Maria. O ator e seus duplos: máscaras, bonecos, objetos. São Paulo: EDUSP, 2001. 16 p. de fotos ISBN 8573592273 (broch.)

AMARAL, Ana Maria. Teatro de animação: da teoria à prática. São Caetano do Sul: Ateliê editorial, 1997. 126 p. ISBN 8585851252 (broch.)

Folha de São Paulo 20 de junho de 1998.

Álvaro Apocalypse. 
HOUDART, Dominique. "Manifeste por un théâtre de marionette et de figure"Manifesto por um teatro de marionete e de figura, in Théatre/Public. Gennevilliers: Théâtre de Gennevilliers, 2000. Tradução de José Ronaldo FALEIRO. (Inédito) OLIVEIRA, Sandra R. Ramalho e. Leitura de imagens para a educação. São Paulo: Programa de Estudos Pós-Graduados em Educação e Semiótica/PUC, 1998. 226p. 